\title{
The Impact of Interactive Conceptual Instruction on Students in High School Physics
}

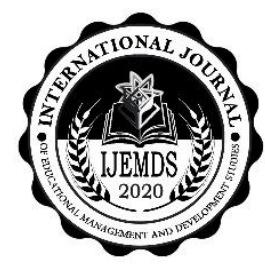

\author{
${ }^{1}$ Dr. Padauk Win \& ${ }^{2}$ Dr. Swe Swe Nyunt
}

\begin{abstract}
The paper evaluated the impact of the interactive conceptual instruction in studying physics at the basic education high school level. The research used an experimental design through the pretest and posttest control group. The randomly selected samples were high schools students from Sagaing, Mandalay and Nay Pyi Taw regions. The ANCOVA results showed a statistical significant difference between the performance of the students who received interactive conceptual instruction and those who did not. Moreover, the qualitative data also supported the quantitative findings. The research findings proved that interactive conceptual model has positive contribution to the teaching of physics at the high school level. As the study explored effective ways to learn physics, the results were valuable inputs in the teaching and learning. It serves as a guide in constructing interactive conceptual instruction lessons in the effective teaching of physics.
\end{abstract}

Keywords:

interactive conceptual instruction, physics, concept, interactive

Suggested Citation: Padauk Win \& Swe Swe Nyunt (2021). The Impact of Interactive Conceptual Instruction on Students in High School Physics. International Journal of Educational Management and Development Studies, Volume 2, Issue 4, pp. 1 - 23.

About the authors:

${ }^{1}$ Corresponding Author. Lecturer, Methodology Department, Sagaing University of Education

${ }^{2}$ Professor, Methodology Department, Sagaing University of Education 


\section{Introduction}

No teacher education program is complete without a course on educational philosophy. To have a philosophy, one must be a philosopher, a "lover of wisdom" pointed out by Stoff and Schwartzberg (n.d.) as cited in Khin Zaw (2001). The two key words, "love" and "wisdom" are particularly applicable to education at this point in its history as being heard less frequently. This was supported by the teachings of Jean Piaget on the prerequisite of progressive education to provide a diverse methodology based on the combination of the learning and independent work activities with the cooperation, group learning and interdependent work activities. From the multitude of teaching methods, teachers focused on the interactive ones because the modern ways of stimulating learning and personal development had dramatically changed. These interactive methods foster the interchange of ideas, experiences, and knowledge.

The implementation of certain modern teaching tools involves a set of skills and capabilities of the teacher such as receptivity to novelty, teaching style adaptation, mobilization, desire for self-improvement, reflective and modern thinking, creativity, and intelligence to accept novelty and flexibility in the way of thinking (Atanasescu \& Dumitru, 2005). To obtain an effective teaching-learning process, interaction between teachers and students applied with the suitable teaching method is vital to raise the standard of learning. Similarly, to address the challenges of the knowledge economy, teachers need to learn the appropriate technology. These can be applied in the teaching of different subjects specially science.

In the teaching of science, teachers can use different ways for developing scientific attitude among the pupils. By teaching physics concepts for example, teachers aim at bringing about a desirable behavioral change among the pupils. In order to make students learn effectively, teacher has to adopt the right method of teaching for a given situation. Every teacher must be familiar with different methods of teaching. Moreover, there are also plans to make language learning more student-centered by using more interactive methods to develop scientific attitude. Therefore, teachers need to apply interactive conceptual instruction in the effective teaching-learning process. 
The study of physics is crucial to the understanding of the world around, inside, and beyond (Gibbs, 2003 as cited in Buabeng, 2015). In many respects, physics is the most basic and fundamental natural science as it involves universal laws and studies behaviour and relationships among a wide range of important physical phenomena (Cutnell \& Johnson, 2007 as cited in Buabeng, 2015). It encompasses the study of the universe from the largest galaxies to the smallest subatomic particles. Moreover, it is the basis of many other sciences such as chemistry, oceanography, seismology, and astronomy. Therefore, learning experiences of physics concept in schools provided by physics teachers are very important.

A study on physics classroom engagement by Dewey and Dykstra (2008) cited in Khwanda (2009) stated that a teaching based on the folk theory failed in engaging students to develop new understanding which suggest for new alternative models of instruction that are student understanding-driven. Dewey and Dykstra (2008) cited in Khwanda (2009) further suggested that teachers should change the teaching to make use of new models of instructions that engage students in constructing their own knowledge in order to enhance the students' conceptual understanding in physics. The gap between the expected achievement and the actual achievement in physics is due to the weakness of students in physics. This major factor causes underachievement due to lack of interactive instruction in studying physics. Therefore, interactive conceptual instruction should be applied effectively for effective teaching-learning process.

In the present "age of science", knowledge of physics is essential to take up certain professional and applied courses such as engineering, medicines, technology and space among others. It is essential for everybody because of its immense value in everyday life (Kumar, 1995). Therefore, physics is the key to many doors of opportunity that open up to challenging, meaningful, rewarding careers in industry, government, academia, and the private sectors (Dayal, 2012).

Given the gap in the teaching of physics and the various applications of the physics knowledge, this study aims to:

1. Construct an interactive conceptual instruction model for learning physics concept;

2. Apply interactive conceptual instruction as a central aspect in teaching physics at the high school level; 
3. Investigate the impact of interactive conceptual instruction in studying physics; and

4. Highlight the difference between the performance of the students with interactive conceptual instruction and those who do not.

The study hypotheses include:

1. There is a significant difference between the achievement of Grade 10 students in physics with and without the interactive conceptual instruction.

2. Students taught with the interactive conceptual instruction have positive attitudes towards the method.

3. The teachers who taught the experimental groups have positive attitudes towards the interactive conceptual instruction.

\section{Literature Review}

\subsection{Theoretical Framework}

All learning theories deal with the areas of capacity to learn, role of practice in learning, motivation, understanding and insight, transfer of learning and retention and forgetting (Hilgard, 1986, cited in Khin Zaw, 2001). These theories pointed that meaningful materials and tasks are learned more readily than materials and tasks not understood by the learner. Moreover, McConnell (1942) as cited in Khin Zaw (2001) finds that the success of the individual learning is dependent upon the ability to discriminate between differences and generalize between similarities.

Constructivist theories encourage the development of critical thinking and understanding of big ideas rather than the mastery of factual information. These contend that students who have a sound understanding of important principles that were developed through their own critical thinking will be better prepared for the complex, technological world. The nature of constructivist learning is active. It is the interaction of ideas and processes. New knowledge is built on prior knowledge. Learning is enhanced when situated in contexts that students find familiar and meaningful. According to Collins (2002), cited in Biggers (2013), it is augmented when students engage in discussions of the ideas and processes involved.

Constructivism is an educational theory that emphasizes hand-on activity-based teaching and learning that students develop their own frames of thought. It focuses on the 
personalized way a learner internalizes, shapes or transforms information. Learning occurs through the construction of new personalized understanding that results from the emergence of new cognitive structures. The constructivist teacher proposes situations that encourage students to think. Rather than leading students toward a particular answer, the constructivist teacher allows students to develop their own ideas and their own pathways. In the constructivist class activity, the nature of the learner is active, the nature of the subject matter is authentic to real life, and thinking approach is divergent.

\subsection{The Instructional Model}

Learning is also the process of acquiring new information, whereas memory refers to the persistence of learning in a state that can be revealed at a later time (Squire, 1987, cited in Gazzaniga, et al., 2002). Learning and memory can be subdivided into major hypothetical stages: encoding, storage, and retrieval. Encoding refers to the processing of income information to be stored. It has two separate steps: acquisition and consolidation. Acquisition registers inputs in sensory buffers and sensory analysis stages, while consolidation creates a stronger representation over time. Storage, the result of acquisition and consolidation, creates and maintains a permanent record. Finally, retrieval utilizes stored information to create a conscious representation or to execute a learned behavior like a motor act (Gazzaniga, et al., 2002).

Transfer of learning between tasks is enhanced where the teacher cues learners into the specific skill being learned and encourages them to reflect on its potential for transfer. Meanwhile, pupils are enhancing their thinking process. The activities are designed to create 'cognitive conflict', that is a dissonance which occurs when a child is confronted with an event which she or he explains when using his/ her current conceptual framework or method of processing data (Adey, 1992:138, cited in Bartlett \& Burton, 2012). Moreover, the proposed model is constructed taking the elements of Glaser's basic teaching model, Talyzina's psychological cybernetic model, Stolurow and Davis's computer-based model, Flanders's interaction analysis model, Dr Khin Zaw's multimodal model, and Gredler's selecting instructional events and theories of memory. 


\section{Figure 1}

Teaching Model for Interactive Conceptual Instruction

Part 1: Conceptual focus

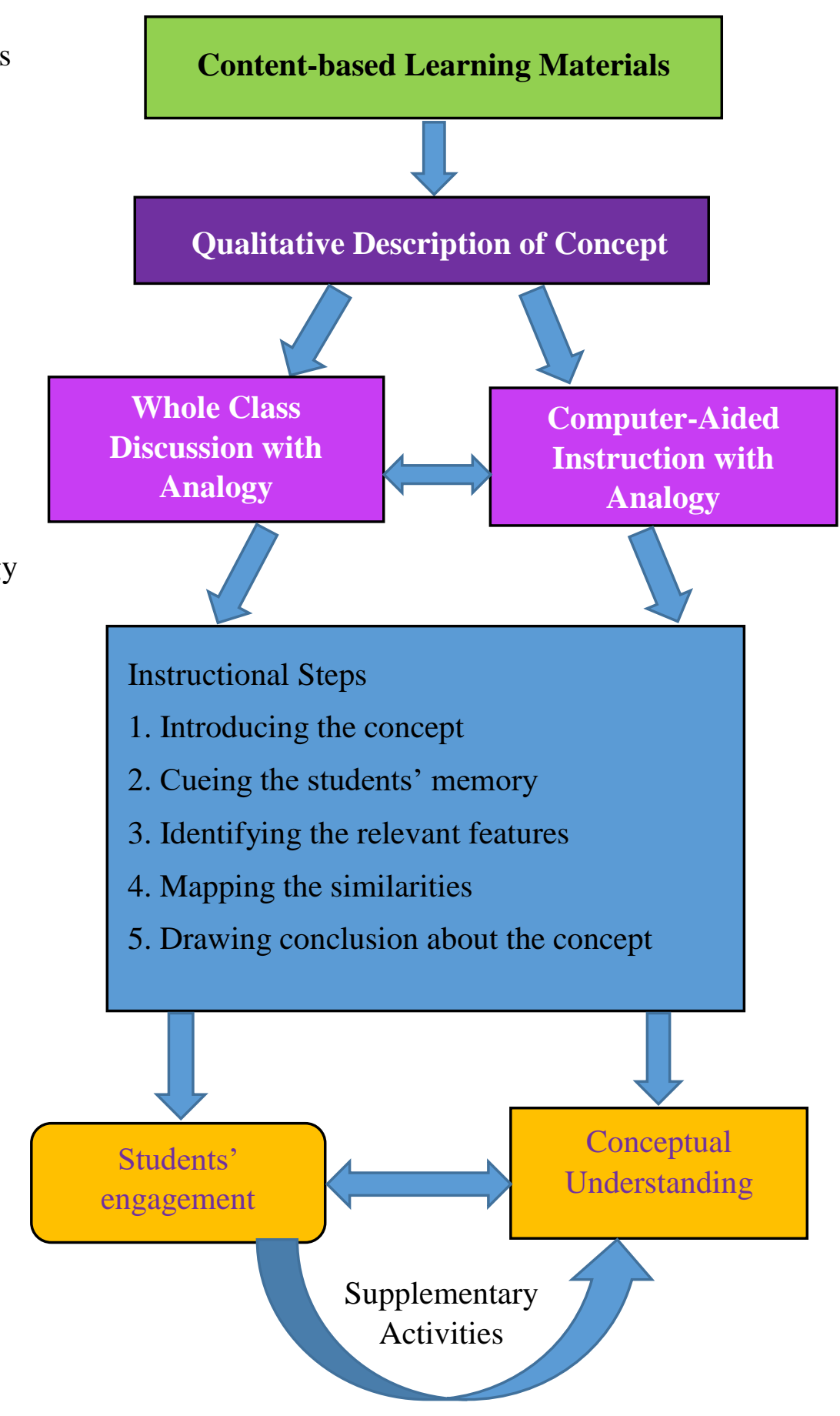

Part 2: Classroom

Interaction with Analogy

Part 3: Results and Reflection

The integrated interactive conceptual instruction model by Khwanda, et al. (n.d.) was adapted to form the interactive conceptual instruction. In this model, research-based learning 
materials are replaced by content-based learning materials in part one of the conceptual focus. Moreover, classroom interaction is linked with analogy during the part two. Meanwhile, teaching with analogy (TWA) model by Alice (2011) is adapted for interactive conceptual instruction in part two. From the six-step TWA model, the five steps were considered to enhance conceptual understanding of the whole course of physics in the high school level. Finally, results and reflection were included to highlight the students' engagement and conceptual understanding. In this part, supplementary activities were discussed for interactive conceptual instruction.

Based on previous models and a set of instructional events, the new design was constructed with three parts in the figure 1.

In part one, conceptual focus is presented and discussed with the students. A different colour is used for the content-based learning materials to understand clearly and choose the content-based learning materials prescribed in basic education curriculum. The aim of this part is to develop conceptual understanding using content-based learning materials as the link. Content-based learning materials are prescribed at the high school level in order to promote students' conceptual understanding about physics. The contents of Grade 10 covers the whole course for a student in physics at the upper secondary level of basic education. The division and order of subject content in separate fields presented in the whole course of upper secondary level physics are mechanics, heat, waves and sound, (4) optics, electricity and magnetism, and modern physics. The contents of chapters were also chosen systematically and were regarded as indispensable for the future understanding of other topics. Without initiating to study mechanics, it is not easy to study other topics. Thus the contents of Grade 10 are overlapped and linked with one another. This part deals with gaining the entering behaviors of students by using content-based learning materials and concept tests, questions and demonstrations to initiate classroom discussion in line with cognitive conflict strategies.

In part two, classroom interaction with analogy is considered for interactive conceptual instruction. The violet colour is used for qualitative description of concept and lilac colour for the others words. Different colours are used to be distinct the concepts of physics and the instructional steps for gaining these concepts. This stage is to promote classroom interactions by using whole class discussion with analogy and computer aided 
instruction with analogy. Students' interaction is the key element of constructivist theory and therefore students' prior knowledge has to be taken into account. In this stage, a concept is discussed with analogy and computer aided instruction to gain more qualitative understanding. The reversible arrow shows the relationship between whole class discussion with analogy and computer-aided instruction with analogy. This suggests the use of one of them to gain the qualitative description of the concept. Some of the lessons such as mechanics, heat, waves and sounds, and optics are suitable with the whole class discussion. The lessons of Pascal's law, transfer of heat, resonance column and organ pipe, refraction of light and laws of refraction, refractive index and formation of images by lenses are prepared by whole class discussion with analogy. However, other concepts such as electricity and magnetism and modern physics are suitable with computer-aided instruction. The lessons of electric lines of force, lightning conductor, electric potential of the earth, capacitance, current and electric circuit, electronic logic gate, and X-rays are prepared by computer aided instruction with analogy. If necessary, teachers should use both whole class discussion and computer-aided instruction in order for students to understand the explanations more according to the time and circumstances of the school and to draw students' attention. The qualitative description of the concept and teaching with analogy can be done to draw the conclusion about the concepts. The five steps of analogy were considered to develop the qualitative description of concepts. There are five steps in this part as follow:

\section{(i) Introducing the concept}

This step is a brief introduction to a full explanation depending on how the analogy is to be utilized. If the analogy is to be used as an advanced organizer, then the concept would be introduced. The analogy may also be used for reviewing the concept(s) in which case, the concepts is fully taught at this stage.

\section{(ii) Cueing the student's memory}

This step involves the introduction of the analogy and determines the student level of familiarity through questioning and/or discussion. If the students' level of understanding is low, the analogy is modified or the process is aborted. The teacher should ensure that there is at least one obvious similarity for the students between the analogy and the target. 


\section{(iii) Identifying the relevant features}

This step involves explaining the analogy to the students at a level that is appropriate to their understanding and which will accurately identify the features of the analogy that was used to build concepts in the next stage.

\section{(iv) Mapping the similarities}

The analogy features are linked with the target concepts. The conceptual map may have a converge on a single target concept or develop two or more target concepts.

\section{(v) Drawing conclusions about the concept}

After mapping the similarities, a summary of what has been learned about the target concept from the analogy should be stated to facilitate student learning. Moreover, to sum up the lesson by grasping the concepts, the teacher must ask the questions that deal with the target lesson. If necessary, teachers have to give feedback and correct the weak points of the students. Therefore, all stages are overlapped and linked with one another. For example, the qualitative description of the concept for mechanics, heat, wave and sound, optics, electricity and magnetism, and modern physics can be discussed and presented by this model.

In part three, the stage of the results and reflection is to describe the students' engagement and reflect conceptual understanding. This stage involves assessment and feedback. The questions and concept tests are prepared and asked to grasp the concepts of the lessons. The reversible arrow shows the results of not only the students' active participation but also the conceptual understanding. If necessary, supplementary activities are needed to provide the students who have misconceptions and conceptual difficulties.

\section{Methodology}

This research aims to study the impact of interactive conceptual instruction on students in studying physics at the basic education high school level. Quantitative research method was used to compare students' achievement in studying physics between the two groups: experimental and control groups. For the qualitative part, two questionnaires for teachers and students were also constructed. 


\subsection{Quantitative Research Method}

Table 1

Experimental Design

\begin{tabular}{lccc}
\multicolumn{1}{c}{ Group } & Pretest (T1) & Treatment & Posttest (T2) \\
\hline Experimental & T1 & Interactive Conceptual Instruction & T2 \\
Control & T1 & Conventional Teaching Method & T2 \\
\hline
\end{tabular}

The Non-equivalent Control Group Design, the Quasi-Experimental design in the explanatory sequential (QUAN $\rightarrow$ qual) was used (Gay \& Mills, 2016). The design of the study is as follows:

\subsection{Subjects}

Participants in this study were 438 Grade 10 students from the selected schools. Population and sample size for five selected schools are presented in Table 2.

Table 2

Population and Sample Size

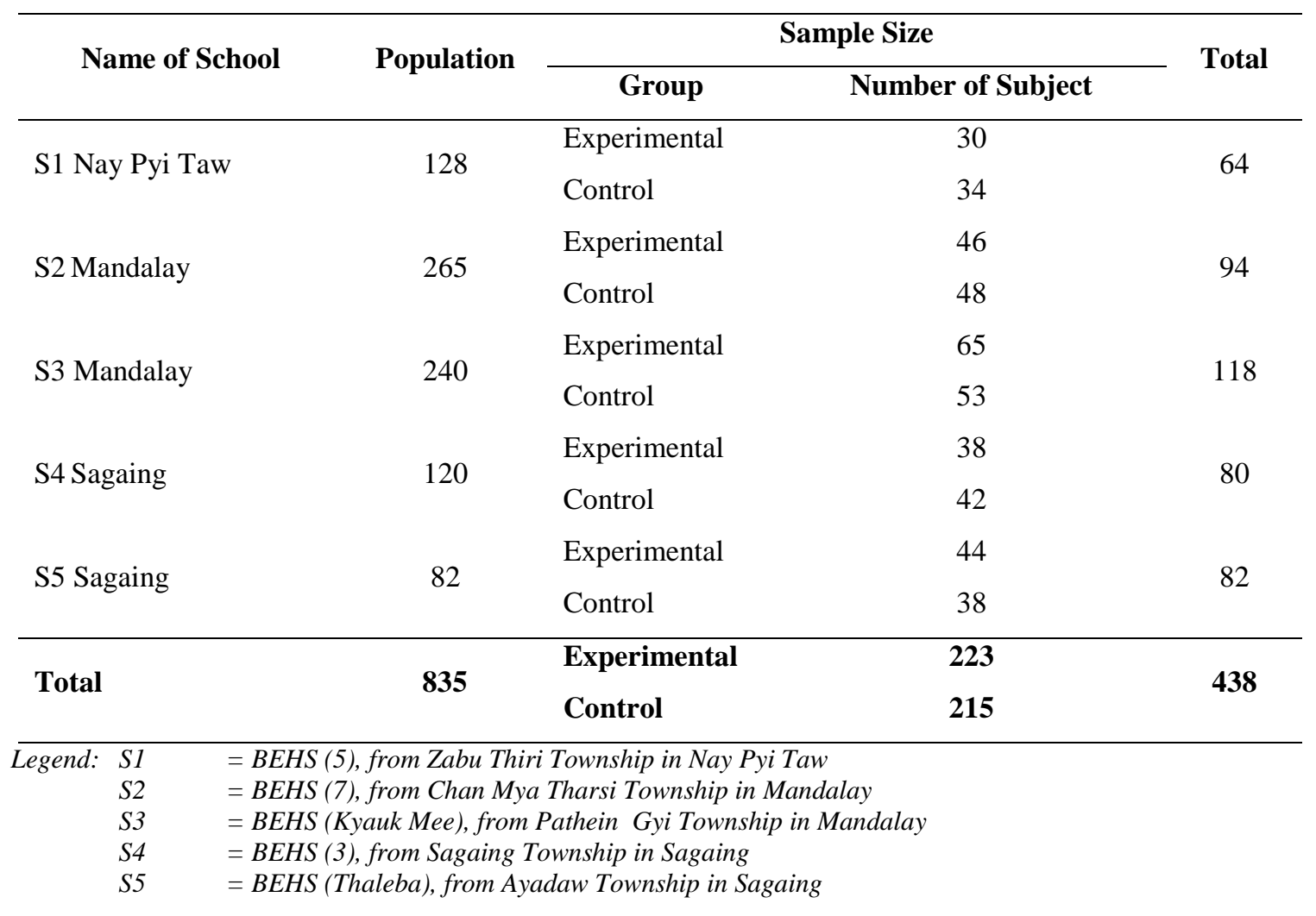


Five Basic Education High Schools in Nay Pyi Taw, Mandalay and Sagaing Region in Myanmar were randomly selected by the use of simple random sampling method to carry out the research. One high school from Nay Pyi Taw, two high schools from Mandalay and two high schools from Sagaing were administered in order to get the required data for this study. Further, two intact groups in each school were randomly assigned as the experimental and control groups.

Only experimental groups from the selected schools participated in qualitative study. The sample size for qualitative study can be seen in Table 3.

Table 3

Population and Sample Size for Qualitative Study

\begin{tabular}{lcccc}
\hline Sample Region & $\begin{array}{c}\text { Sample } \\
\text { Schools }\end{array}$ & $\begin{array}{c}\text { Sample Teachers for } \\
\text { Questionnaire }\end{array}$ & $\begin{array}{c}\text { Sample Teachers for } \\
\text { Interview }\end{array}$ & $\begin{array}{c}\text { Sample } \\
\text { Students }\end{array}$ \\
\hline Nay Pyi taw & S1 & 1 & 1 & 30 \\
Mandalay & S2 & 1 & 1 & 46 \\
Mandalay & S3 & 1 & 1 & 65 \\
Sagaing & S4 & 1 & 1 & 38 \\
Sagaing & S5 & 1 & 1 & 44 \\
\hline Total & & $\mathbf{5}$ & $\mathbf{5}$ & $\mathbf{2 2 3}$ \\
\hline
\end{tabular}

\subsection{Instruments}

The instruments were constructed in accordance with the selected research design. Therefore, (1) a pre-test and its marking scheme, (2) a post-test and its marking scheme were used. They were developed under the guidance of supervisor and co-supervisor. In order to establish validity, they were presented to teacher educators and academicians. According to their valuable suggestions, some items were modified.

\subsubsection{Pre-test}

By the nature of Grade 10 Physics, it contains new terms, symbols, measurement, systems and concept-related equations. This research is mainly concerned with the study of interactive conceptual instruction on students in studying physics at the basic education high school level. A pre-test measures the initial ability of the selected sample students. The pretest items were based on the first three chapters of the physics textbooks. Objective test items were used. There were no identical concepts among these items. Both the recall and 
recognition items were used to see initial ability of the sample students. Test items were mainly related to the concept of physics and measurement, vectors and describing motion. In an alternative way, those concepts are very basic to study further. Without having thorough knowledge in those basic concepts, a student cannot achieve the mastery level in physics learning. Item format and the number of test items were formed to represent the criteria for measuring instrument, which has content validity and construct validity.

\subsubsection{Post-test}

The effectiveness of the instructional design or model in studying physics is necessary in basic education high school. According to the allocation of the curriculum and syllabus for August, September and October, Chapters 4, 5 and 6 of physics were selected as a valid content for this test. In more details, 16 lessons plans for physics were used to construct the post-test items of part A and B.

Part A contains eight objective test items. Each item is concerned with a physics concept. Part A assesses the recognition and application level of the learners on the concept of subject terms and definitions and calculation. Part B contains six items, which include calculation. Specifically, item 1 represents right calculation about the concept of density and weight and; item 2 represents to solve the problems for right concept of pressure. Similarly, item 3 and 4 are concerned with the calculation of the concept about the kinetic energy and potential energy. Moreover, item 5 represents to solve the problems for the right concept of the linear expansion and item 6 is concerned to solve the calculation with the concept of temperature on the Celsius scale and Fahrenheit scale. All items in this part assess the learners' comprehension and concept. The time allowed is 1 hour 30 minutes. The post-test includes Part A for objective items and simple calculation while part B for complex calculation items. Like pre-test items, the post-test items were based on four types of test validity, item validity, sampling validity, construct validity and consequential validity. Content validity was through measuring 17 items that represent the intended content area or all physics concepts learned from the selected learning materials. Moreover, the pre-test and post-test items were structured with the simple wording. These items do not contain the facts that can diminish the validity of a test and instruments, such as unclear test items, ambiguous test items, difficult vocabulary, complex sentence structures, untaught test items and 
inconsistent and subjective scoring methods. Finally, the test items were verified by experts' judgments and advices to become a good measuring instrument.

\subsection{Learning Materials}

Physics concepts must be explained with the excellent learning materials. Students cannot automatically acquire conceptual understanding. Therefore, studying the physics concept is essential for the students in the basic education high school level systematically. So learning materials have been developed based on the interactive conceptual instruction. Among the 10 chapters, only three chapters were chosen for teaching experiment because of the time limit. It is assumed that these three chapters can cover all the physics concepts of interactive conceptual instruction at the high school level. The lessons were developed into sample lessons plans for new instructional design. Every lesson contains a concept, which relates to equation including identification of symbols, sign convention, unit system and illustration with diagrams. The most important procedure is presenting qualitative description of concept. It must be supported with conceptual focus, classroom interaction with analogy and result and reflection. These steps have to be practiced with examples, questions and textbook exercises.

\subsection{Procedure}

The independent variables in this study were the different instructions of physics teaching. Therefore, the independent variable for experimental group was instruction using interactive conceptual instruction and for control group was instruction without using it. The dependent variable was student's score on the posttest.

Firstly, in order to evaluate the feasibility of the instruments for full-scale study, pilot experiment was conducted at Practicing High School (Shwe Min Wun), Sagaing University of Education from July 15 to August 10, 2018. The time taken for teaching including testing before and after was 22 class sessions, each of which lasted 45 minutes. The study was carried out according to quasi-experimental design. The number of participants were 50 for experimental group and 47 for the control group. In the light of experiences of pilot study, necessary changes in testing and planning for experimental study were made. Before pilot study it was predicted to take 4 class sessions for teaching a chapter, but in reality it took 6 class sessions for a chapter. Thus, time allocation was changed. In order to establish the 
reliability of the pretest, a pilot study was carried out with 50 Grade 10 students at Practicing High School (Shwe Min Wun). According to pilot study, the internal consistency of the test, the reliability coefficient, Cronbach's Alpha was 0.77 of the pretest included 50 items. Pilot teaching also gave better ideas for the interactive conceptual instruction to motivate students' interest in learning.

Conducting full-scale experimental study was started in all five selected schools in August 2018. At the beginning of the study, all participants in both groups were tested to check the equivalence of the two groups. It took 1.5 hours for the 2 class sessions. Afterwards, the experimental groups were treated with the interactive conceptual instruction while the control groups were taught the usual. After the treatment period, post-test was administered to all students in experimental groups and control groups to measure the interactive conceptual instruction. The post-test took 1.5 hours for 2 class periods. The experimental study finished in November 2018.

Data collection process was carried out in November 2018. The questionnaire was administered to all students and teachers who participated in experimental groups in all five selected schools.

\subsection{Data Analysis}

The statistical package for the social science (SPSS) version 22 was used to analyze the quantitative data. The data were analyzed using ANCOVA test to compare the differences between the experimental groups and control groups.

\section{Findings and Discussion}

This study is mainly concerned with the analysis of data, findings and interpretation of the experimental study to ascertain the impact of interactive conceptual instruction on students in studying physics at the basic education high school level. This study deals with research findings based on quantitative and qualitative studies. 


\subsection{Quantitative Findings}

Table 4

Analysis of Covariance on the Pre-test Scores by Schools

\begin{tabular}{|c|c|c|c|c|c|c|c|}
\hline School & Group & $\mathbf{N}$ & $\mathbf{M}$ & SD & Ms & $\mathbf{F}$ & $\mathbf{p}$ \\
\hline \multirow{2}{*}{ S1 } & Experimental & 30 & 39.06 & 4.30 & \multirow{2}{*}{56.94} & \multirow{2}{*}{0.206} & \multirow{2}{*}{$0.206(\mathrm{NS})$} \\
\hline & Control & 34 & 37.17 & 7.01 & & & \\
\hline \multirow{2}{*}{ S2 } & Experimental & 46 & 29.00 & 7.15 & \multirow{2}{*}{34.29} & \multirow{2}{*}{0.567} & \multirow{2}{*}{$0.453(\mathrm{NS})$} \\
\hline & Control & 48 & 30.20 & 8.33 & & & \\
\hline \multirow{2}{*}{ S3 } & Experimental & 65 & 39.20 & 4.51 & \multirow{2}{*}{2.46} & \multirow{2}{*}{0.137} & \multirow{2}{*}{0.712 (NS) } \\
\hline & Control & 53 & 39.49 & 3.88 & & & \\
\hline \multirow{2}{*}{ S4 } & Experimental & 38 & 33.47 & 4.38 & \multirow{2}{*}{4.12} & \multirow{2}{*}{0.206} & \multirow{2}{*}{$0.651(\mathrm{NS})$} \\
\hline & Control & 42 & 33.92 & 4.56 & & & \\
\hline \multirow{2}{*}{ S5 } & Experimental & 44 & 31.27 & 5.03 & \multirow{2}{*}{62.18} & \multirow{2}{*}{2.882} & \multirow{2}{*}{0.093 (NS) } \\
\hline & Control & 38 & 29.52 & 4.14 & & & \\
\hline \multirow{2}{*}{ Total } & Experimental & 223 & $\mathbf{3 4 . 5 3}$ & 6.67 & \multirow{2}{*}{12.17} & \multirow{2}{*}{0.260} & \multirow{2}{*}{0.611 (NS) } \\
\hline & Control & 215 & 34.20 & 7.01 & & & \\
\hline
\end{tabular}

Legend: $N S=$ no significance

There was no significant difference between the mean of the experimental group and control group in all schools before they were treated. From these data, it can be interpreted that both groups in each school started with the same initial ability.

Table 5 shows that the mean of the experimental group in each school was significantly higher than that of the control group. It also indicated that there was a significant difference at $p<.001$ between the post-test scores of the two groups in all the schools.

From the findings, it can be interpreted that the use of interactive conceptual instruction had significant effect on students' achievement in physics. Therefore, the students of the experimental groups gained significant positive effect due to the interactive conceptual instruction at some cognitive levels (i.e. remembering, understanding and applying level). 
Table 5

Analysis of Covariance on Overall Post-test Means

\begin{tabular}{clcccccc}
\hline School & \multicolumn{1}{c}{ Group } & N & M & SD & Ms & F & p \\
\hline \multirow{2}{*}{ S1 } & Experimental & 30 & 45.58 & 2.704 & & & \\
& Control & 34 & 36.50 & 9.031 & 1312.39 & 27.63 & $.000^{* * * *}$ \\
& Experimental & 46 & 33.21 & 8.896 & & & \\
S2 & Control & 48 & 17.07 & 5.840 & 5922.95 & 107.86 & $.000^{* * * *}$ \\
& Experimental & 65 & 45.33 & 3.42 & & & \\
S3 & Control & 53 & 41.05 & 6.846 & 5555.80 & \multirow{2}{*}{19.39} & $.000^{* * *}$ \\
& Experimental & 38 & 30.27 & 9.32 & & & \\
& Control & 42 & 18.67 & 9.95 & 2632.20 & 29.7 & $.000^{* * * *}$ \\
\multirow{2}{*}{ S5 } & Experimental & 44 & 40.05 & 4.994 & & & \\
& Control & 38 & 34.67 & 6.056 & 533.883 & \multirow{2}{*}{17.487} & $.000^{* * *}$ \\
\multirow{2}{*}{ Total } & Experimental & $\mathbf{2 2 3}$ & $\mathbf{3 9 . 2 6}$ & $\mathbf{8 . 8 0 0}$ & $\mathbf{1 1 4 7 8 . 3 7}$ & $\mathbf{1 0 2 . 6 3}$ & $\mathbf{. 0 0 0 * * *}$ \\
\hline
\end{tabular}

$* * * p<.001$

Table 6 indicates that the means of the experimental groups were significantly higher than those of the control groups in all schools. At the remembering level, there was a significant difference in the means of the two groups at $p<.001$ in school 1 , school 3 and school 5 but there was no significant difference between the mean of the experimental and control groups in school 2 and school 4.

Table 6

Analysis of Covariance on Remembering Level

\begin{tabular}{|c|c|c|c|c|c|c|c|}
\hline School & Group & $\mathbf{N}$ & M & SD & Ms & $\mathbf{F}$ & $\mathbf{p}$ \\
\hline \multirow{2}{*}{ S1 } & Experimental & 30 & 11.43 & 1.250 & \multirow{2}{*}{97.30} & \multirow{2}{*}{20.711} & \multirow{2}{*}{$.000 * * *$} \\
\hline & Control & 34 & 7.67 & 2.716 & & & \\
\hline \multirow{2}{*}{ S2 } & Experimental & 46 & 4.48 & 1.907 & \multirow{2}{*}{1.78} & \multirow{2}{*}{0.691} & .408 \\
\hline & Control & 48 & 4.75 & 1.2333 & & & (ns) \\
\hline \multirow{2}{*}{ S3 } & Experimental & 65 & 9.13 & 1.020 & \multirow{2}{*}{22.48} & \multirow{2}{*}{22.502} & \multirow{2}{*}{$.000 * * *$} \\
\hline & Control & 53 & 8.18 & .966 & & & \\
\hline \multirow{2}{*}{ S4 } & Experimental & 38 & 4.15 & 1.636 & \multirow{2}{*}{1.63} & \multirow{2}{*}{0.478} & .492 \\
\hline & Control & 42 & 3.86 & 2.00 & & & (ns) \\
\hline \multirow{2}{*}{ S5 } & Experimental & 44 & 8.47 & 1.454 & \multirow{2}{*}{31.67} & \multirow{2}{*}{14.05} & \multirow{2}{*}{$.000 * * *$} \\
\hline & Control & 38 & 7.10 & 1.586 & & & \\
\hline \multirow{2}{*}{ Total } & Experimental & 223 & 7.50 & 2.991 & \multirow{2}{*}{193.82} & \multirow{2}{*}{27.55} & \multirow{2}{*}{$.000 * * *$} \\
\hline & Control & 215 & 6.29 & 2.423 & & & \\
\hline
\end{tabular}

Note: $* * * p<.001, \mathrm{NS}=$ no significance 
These findings reflect that the group of experimental students who received interactive conceptual instruction were found to have more effective achievement than the group of control students. However, school 2 and school 4 have the same achievement between the experimental and control group for the remembering level. It can be interpreted that the students in these schools have good prior knowledge of physics concept and very active in the teaching-learning process. Moreover, one teacher is assigned for both Grade 10 and Grade 11 of school 2 and school 4 due to inadequacy of teachers in these schools. In addition, the teacher in school 4 has no physics specialization.

Table 7

Analysis of Covariance on Understanding Level Items

\begin{tabular}{|c|c|c|c|c|c|c|c|}
\hline School & Group & $\mathbf{N}$ & $\mathbf{M}$ & SD & Ms & $\mathbf{F}$ & $\mathbf{p}$ \\
\hline \multirow{2}{*}{ S1 } & Experimental & 30 & 11.86 & 1.814 & \multirow{2}{*}{3.77} & \multirow{2}{*}{1.50} & \multirow{2}{*}{$0.225 \mathrm{NS}$} \\
\hline & Control & 34 & 12.07 & 1.360 & & & \\
\hline \multirow{2}{*}{ S2 } & Experimental & 46 & 11.25 & 1.669 & \multirow{2}{*}{13.50} & \multirow{2}{*}{4.04} & \multirow{2}{*}{$0.047^{*}$} \\
\hline & Control & 48 & 7.29 & 2.681 & & & \\
\hline \multirow{2}{*}{ S3 } & Experimental & 65 & 12.57 & .786 & \multirow{2}{*}{2.56} & \multirow{2}{*}{6.57} & \multirow{2}{*}{$0.012^{*}$} \\
\hline & Control & 53 & 12.00 & 1.754 & & & \\
\hline \multirow[b]{2}{*}{ S4 } & Experimental & 38 & 7.88 & 2.077 & \multirow{2}{*}{147.72} & \multirow{2}{*}{27.65} & \multirow{2}{*}{$.000 * * *$} \\
\hline & Control & 42 & 5.14 & 2.484 & & & \\
\hline \multirow[b]{2}{*}{ S5 } & Experimental & 44 & 9.33 & 2.117 & \multirow{2}{*}{8.13} & \multirow{2}{*}{2.19} & \multirow{2}{*}{$0.143 \mathrm{NS}$} \\
\hline & Control & 38 & 8.71 & 1.650 & & & \\
\hline \multirow{2}{*}{ Total } & Experimental & 223 & 10.76 & 2.400 & \multirow{2}{*}{388.8} & \multirow{2}{*}{39.43} & \multirow{2}{*}{$.000^{* * * *}$} \\
\hline & Control & 215 & 9.03 & 3.398 & & & \\
\hline
\end{tabular}

Note: $* p<.05, * * * p<.001$, ns $=$ no significance

Table 7 reveals that the experimental groups showed a clear superiority over the control groups in the means of understanding level questions in school 2, school 3 and school 4. At the understanding level, there was a statistically significant difference in the means of the two groups at $p<.001$ in school 2 and school 4 and at $p<.05$ in school 3. Among them, there was no significant difference between the experimental and control group for understanding level in school 1 and school 5. 
Furthermore, there was no significant difference between the experimental and control group for understanding level in school 1 and school 5. It can be interpreted that the teachers of control group in school 1 and school 5 taught the students by sharing their knowledge and giving opportunities to discuss physics concepts. The teachers in experimental group taught the physics concepts with the proposed model. Therefore, interactive conceptual instruction tends to be more effective than the formal instruction for students to grasp the meaning of their learned materials. Therefore, interactive conceptual instruction can increase the conceptual understanding. It can be interpreted that all students in these schools have the excellent eagerness and attention in studying physics.

\section{Table 8}

Analysis of Covariance on Applying Level Items

\begin{tabular}{|c|c|c|c|c|c|c|c|}
\hline School & Group & $\mathbf{N}$ & $\mathbf{M}$ & SD & Ms & $\mathbf{F}$ & $\mathbf{p}$ \\
\hline \multirow[b]{2}{*}{ S1 } & Experimental & 30 & 22.28 & 1.472 & \multirow[b]{2}{*}{379.67} & \multirow[b]{2}{*}{16.04} & \multirow[b]{2}{*}{$.000 * * *$} \\
\hline & Control & 34 & 16.63 & 6.558 & & & \\
\hline \multirow{2}{*}{ S2 } & Experimental & 46 & 17.47 & 6.848 & \multirow{2}{*}{34.61} & \multirow{2}{*}{119.99} & \multirow{2}{*}{$.000 * * *$} \\
\hline & Control & 48 & 5.06 & 3.949 & & & \\
\hline \multirow{2}{*}{ S3 } & Experimental & 65 & 23.69 & 3.199 & \multirow{2}{*}{242.76} & \multirow{2}{*}{12.96} & \multirow{2}{*}{$.000 * * *$} \\
\hline & Control & 53 & 20.79 & 5.372 & & & \\
\hline \multirow[b]{2}{*}{ S4 } & Experimental & 38 & 18.13 & 6.760 & \multirow{2}{*}{1397.88} & \multirow[b]{2}{*}{31.95} & \multirow[b]{2}{*}{$.000 * * *$} \\
\hline & Control & 42 & 9.66 & 6.494 & & & \\
\hline \multirow{2}{*}{ S5 } & Experimental & 44 & 22.45 & 3.108 & \multirow{2}{*}{227.49} & \multirow{2}{*}{16.69} & \multirow{2}{*}{$.000 * * *$} \\
\hline & Control & 38 & 19.11 & 4.232 & & & \\
\hline \multirow{2}{*}{ Total } & Experimental & 223 & 21.02 & 5.382 & \multirow{2}{*}{5577.03} & \multirow{2}{*}{122.15} & \multirow{2}{*}{$.000 * * *$} \\
\hline & Control & 215 & 14.12 & 8.153 & & & \\
\hline
\end{tabular}

Note: $* * * p<.001$

Table 8 shows that the mean of the experimental group was significantly higher than that of the control group in all schools. This indicates that there was a significant difference at $p<.001$ on the mean of application level items in all schools. 


\subsection{Findings from Teachers' Interview and Students' responses}

In order to obtain in-depth information of the teachers' attitudes towards the proposed interactive conceptual instruction model and learning activities through this model and teaching concept of physics, open questions and interviews were conducted. Five teachers who taught experimental groups in the selected schools were interviewed.

Teacher 1. The first interviewee is a Grade 10 physics teacher from school 1. Her undergraduate degree is Bachelor of Science in Physics and continued the Bachelor in Education degree and Master in Education degree. She had teaching experiences in foreign countries and attended science teaching program for 21 days abroad. Her responses highlight that the prepared learning activities were useful for teaching physics. She studied other physics books such as "O" level. She drew the attention of her students with experiments about physics concept and started experiments and computer aided instruction in her teaching with whole class discussion. She gave equal opportunities to share the opinions and ideas of the students. She even shared her problem solving of physics concept to teachers in her township. She suggested that real objects and teachings aids of physics are needed to raise physics teaching in Myanmar. Moreover, she asserts that sufficient time is necessary for physics teaching, teachers who can lead experiments in physics teaching are needed and the physics curriculum should be regularly upgraded.

Teacher 2. The second interviewee is a Grade 10 and Grade 11 physics teacher from school 2. Her first degree is Bachelor of Science in Botany and has Bachelor in Education degree with specialization of physics and biology. She had experiences with the education training in the government, which were her model experiences of teaching physics. She said that the prepared learning activities were very useful for the teaching of physics. As to her teaching, she handles students of medicine and able to produce students with distinctions in physics. She starts the class with portions of chapters and focuses on physics concept through interactive conceptual instruction. She also uses computer aided-instruction and 
actual experiments in teaching. She observes that students enjoy observations with real objects. She even plans to upgrade the subject and eventually share the teaching method in a district level workshop. She suggests proper time allotment for the teaching of the subject so that repetitions could be properly implemented as these help solve the problems.

Teacher 3. The third interviewee is a Grade 10 physics teacher from school 3. She has Postgraduate Degree and Bachelor in Education. She also had the chance to attend Master in Education degree. She got distinctions in physics and mathematics in the undergraduate course. She discussed the same narratives of an experienced teacher. Moreover, she suggested that the physics should be taught with real objects and interactive conceptual instruction to be effective.

Teacher 4. The fourth participant is a Grade 10 physics teacher from school 4. Her first degree is Bachelor of Science in Zoology. She was afraid of physics and calculation but was forced to teach the subject due to extreme necessity. According to her, the prepared learning activities were very useful for the teaching of physics; the interactive conceptual instruction was very effective in the teaching-learning process. This was her first time to adopt the interactive conceptual instruction and implement the same in the first physics subject in her university. She suggests that teachers guide the Grade 10 and 11 students through the appropriate teaching methods instead of preparing them guide questions for the examination.

Teacher 5 .The last interviewee is a Grade 10 physics teacher from school 5. She got Master of Science in Physics and aimed to become a science teacher since she was in high school. She attends training in their town and discusses key ideas of physics concept with colleagues. According to her, the prepared learning activities were very useful for the teaching of physics. She also noted that the interactive conceptual instruction was very effective in the teaching-learning process. She suggested that physics 
teachers use authentic materials for a more effective teaching. She observed that the students in the experimental group developed positive attitude towards their learning.

\section{Conclusion}

The research aims to develop innovative teaching approaches in the study of physics at the basic education high school level. In this study, quantitative method was used to compare students' physics concept between the two groups. Meanwhile, qualitative method was used to investigate students' attitude towards physics learning, and teachers' attitude towards the attainment of physics concept and the proposed interactive conceptual instruction model. The results showed that performance of students who were taught using the interactive conceptual instruction model were significantly higher than those of the students who were learning with formal instruction.

The results of the study posit that if teachers want the students remember $90 \%$ of the physics topics, the use of experiments and peer learning are highly encouraged. Therefore, conceptual focus and classroom interaction with analogy are must for teaching physics. The interactive conceptual instruction model develops the memory level of students through experiments and computer-aided instruction. In this method, the systematic process of interactive conceptual instruction model begins with conceptual focus and classroom interaction with analogy. Thus, the following instructional steps are recommended: (1) introducing the concept; (2) cueing the students' memory; (3) identifying the relevant features; and (4) mapping the similarities and drawing conclusion about the concept. The method develops student engagement and conceptual understanding through the supplement activities.

The teacher can employ multiple methods or activity sequences that can lead to successful student learning of a specific concept or process skill. Similarly, employment of a variety of concrete and abstract representation and experimental procedures to appeal to the variety of ways students' learning are necessary. Students should be encouraged to arrive at an answer by reasoning rather than by memorization and recall. Finally, the classroom must be a place for meaningful learning that constructs science concepts actively by using the cognitive concept that involve learners themselves. 
The model can be useful to some extent in teaching physics wherein students can learn physics concepts easily. Similarly, the model can serve as basis for other subject areas. Further research on the effectiveness of interactive conceptual instruction model can be developed.

\section{Acknowledgement}

The study is part of the author's dissertation in the PhD program. Sincere gratitude is extended to Dr. Khin Mar Khine, Professor, Head of Methodology Department, Yangon University of Education, Dr. Aye Aye Myint, Professor and Head of Methodology Department (Retired), Sagaing University of Education and Dr. Swe Swe Nyunt, Professor, Sagaing University of Education, dissertation supervisor.

\section{References}

Alice, J. (2011). Effects of teaching-with-analogy on academic performance and retention of evolution concepts among Nigeria certificate ine Biology students. Retrieved April, 5, 2017, from http://kubanniabu.edu.ng>jspui> bitstream

Atanasescu, C. I., \& Dumitru, F. (2005). Interactive teaching-learning methods in the in the interdisplinary approach of natural science from the mentor-teacher's. Retrieved August, 7, 2016 from http://www.upit.ro/.../4820/paper-2.pd.

Barlett, S. \& Burton, D. (2012). Introduction to education studies (3rd ed.). Great Britain by Ashford Colour Press Ltd.

Biggers, M. S. (2013). Elementary teachers' ideas about, planning for, and Implementation of learner-directed and teacher directed inquiry: a mixed methods study. University of Iowa. Retrieved June 8, 2016 from http://ir.uiowa.edu/etd/2438

Buabeng, I. (2015). Teaching and learning of physics in New Zealand and high school. Retrieved August 1, 2016 from http://ir.canterbury.ac.nz/handle/10092/11396

Dayal, D. (2012). Modern methods of teaching physics. New Delhi: APH Publishing Corporation.

Gay, L .R. \& Mills, G. E. (2016). Educational research: competencies for analysis and application. (11th ed.). New York: Pearson Education Limited. 
Gazzaniga, M. S. , Ivry, R. B. \& Mangum, G. R. (2002). Cognitive neuroscience: The biology of the mind. W.W.Norton \& Company, Inc.

Khwanda, M. N. (2009). The impact of interactive-engagement models in the teaching and learning of physics to first year education students. Retrieved July 26, 2016 from http://www.uir.unisa.acza/.../dissertation-\%20Khwan

Khwanda, M. N., Kriek, J. \& Bassom, I. (n.d.). Interactive engagement models in pre-service science teacher understanding of mechanics. Retrieved August 7, from http://www.uir.unisa.ac.za

Khin Zaw, Dr. (2001). Theoretical pedagogy. PhD Programme Course Material. Yangon Institute of Education, Myanmar.

Lasky, B. A., Otto, M.A.\& Morrish, W.(2006). Interactive teaching methodologies. (1st ed.). Community Legal Advisor Educator Mannual- Draft manual. Open Society Justice Initiative.

Ministry of Education. (2014). Grade nine physics textbook. Myanmar: Basic Education Curriculum, Syllabus and Textbook Committee.

Savinainen, A., \& Scott, P. (2002). The force concept inventory: A tool for monitoring student learning. Physics Education, 37(1), 45-52.

Siddiqui, M.H. (2009). Advanced educational psychology. New Delhi: Balaji Offset.

Smith, T. (2001). Oxford dictionary. (10th ed.). Oxford University Press

Walter, E. (2008). Cambridge advanced learner's dictionary. (3rd ed.). Cambridge University Press. 